\title{
Afterword: Special Collections and Assessing the Value of Academic Libraries
}

THE INITIATIVES AND OPERATIONAL STUDIES presented in this issue of RBM reflect a new level of research and analysis in the area of the assessment of special collections and related services. Here I wish to explicitly frame these essays in the larger context that they imply, namely institutional outcomes. The key challenge in special collections - in fact, in any part of the academic library-is getting the broader institution to care. How does one ensure that the university and its stakeholders will be willing to underwrite the support of special collections, arguably the most expensive component of a library as far as acquisitions, skilled professional staff, customized space, preservation, and security? Expecting an appreciation of the intrinsic goodness of special collections won't carry the day even in well-off, prestigious institutions, because - well, because at the top level "it's all about them." Our assessment program has to demonstrate the value of special collections to advancing the mission of the entire library, and in turn the value of the library in contributing to the accomplishment of the university's goals.

University presidents, trustees, and those who hold the purse strings are focused on a handful of overarching goals. Every unit of the university, including the library, needs to link its work and its advocacy to elements of the institutional mission. The general nature of these is predictable but the details are what can give each institution its unique flavor, and it behooves us to take the time to tease out those details and emulate the phrasing we see in the university's own planning documents.

Each angle of the mission may translate into slightly different library services and ways of valuing special collections. Does your campus envision itself as serving or competing against others that serve local, regional, national, or international audiences? What are its degrees of emphasis on undergraduate education, graduate and professional education, faculty and advanced research, clinical and extension services, or civic and community engagement? Is there any sense of an institutional commitment to preserving cultural heritage over the long term, either for research

1. The substance of these remarks was presented at the 52nd annual preconference of the Rare Books and Manuscripts Section of the Association of College and Research Libraries, June 21-24, 2011, Baton Rouge, LA, as part of plenary session titled "How Special Is Your Library? Special Collections and the Value of Academic Libraries." An audio recording of the session is available from the RBMS website at: www.rbms.info/conferences/preconfdocs/2011/2011docs.shtml. 
or for community engagement? This last issue is rarely stated as such, but it may be a crucial one if one wants to argue for sustaining large special collections that may not directly support immediate academic teaching or research needs on campus. We take this goal for granted, but it's a huge risk to do so. Test the assumption by imagining that there are no classes or faculty in a certain field for a couple of years: could you justify the acquisitions and subject specialists in support of that field? Are there external constituencies who would be served, and are those groups important to the top brass? Is there a prestige benefit to the university of advancing the cultural heritage goal for a wider community—and do university administrators and trustees care?

As one digs down beneath the lofty language of "mission" that is touted in university reports and events, there are significant pressures that preoccupy presidents, provosts, and governing bodies. These include the changing demographics and expectations of students, the demands for accountability and performance as well as affordability and sustainability, the constant need to upgrade technologies for learning and research, the concern over maintaining disciplinary relevance, and the growing array of multi-institutional frameworks, such as consortia and joint ventures, within which the university must operate. These are topics that truly worry presidents far more than the daily matters of academic life, barring a crisis or scandal. They are not too interested in the library's internal operating stresses-rather, we have to show how our work can alleviate their stress! How can we help our institutions be more competitive and more financially efficient? What leadership are we contributing to the campus use of innovative technologies or to the articulation of new consortial models? We need to externalize the impact of our work. What do we do that promotes documented outcomes-which may be students getting jobs, faculty getting grants and patents, or extension offices delivering services to the residents of the state? The desired outcomes go back to the articulations and emphases of institutional mission.

To engage with the campus mission and contribute to successful outcomes, libraries and special collections are of course major providers of essential research resources, but that is only the starting point. In today's networked on-demand media environment, faculty and students have many ways to get information without having to engage with formal library structures or services-in other words, without coming through the doors of our buildings or visiting our websites. We must therefore articulate more proactive roles and demonstrate the unique value we can contribute to our campus communities. This value comes as much from our intellectual and technical expertise as from our collections. It is especially relevant in new forms of support for faculty research, but it is equally compelling in customizing services for students and 
in shaping a library presence that enhances the campus community. As librarians, we see ourselves as partners in research and instructional support, and we need to do more to make that partnership meaningful and visible in both directions and to embed it in academic processes such as curriculum design and research proposals. The expertise we have in the creation, organization, and use of diverse information formats can readily be applied in nonlibrary settings-assisting faculty with their own research data, artifactual collections, or journal publishing, for example. In special collections, we routinely offer many services that enhance university outreach and external relations, such as exhibits, events, alumni communications, and presentations for $\mathrm{K}-12$ schools. These programs should be tracked and synthesized such that the effort can be assessed as advancing formal institutional goals.

In demonstrating value to the institution, the term "alignment" can be more useful than "assessment," as it conveys a sense of strategic choice and supportive convergence, which ultimately has more to do with the goals of assessment than operational or transactional measures. Alignment happens through the way that library planning documents and annual reports are written as much as through the activities themselves. We need to ensure that everyone in the library shares common goals and language and then use parallel language for unit-specific planning, including in special collections. We need to choose library emphases strategically and to fit them within campus initiatives, to customize library services to support campus programs and attitudes, to engage with faculty research beyond just delivering library materials (for example, by working jointly on publishing initiatives, research data, and scholarly websites), and to proactively foster internal and external collaborations. Recent library research has adopted the business term "return on investment" (ROI) to make the point that libraries are providing demonstrable value to the university in return for their budget allocations and that the growing amount of dollars required to fund libraries is not merely a dispensable frill. ROI thinking also goes straight back to the definition of university mission. The value to the mission can be demonstrated through assessing the ways that specific library services and resources help in recruiting faculty and graduate students, in securing research grants, in attracting philanthropy, and in producing scholarly publications and technical products such as software or devices. Special collections contribute to all of these dimensions, but we have been disorganized in how we track and report those contributions. Our measurements have often stopped with simply looking at internal processes, without taking the next step and documenting academic results and end-user outcomes. We have a great many useful component measures including those explored in these articles, so the challenge is to aggregate them effectively and frame their meaning in terms relevant to the university. 
Aggregating measures and demonstrating the value of the library requires a less siloed and polarized perception of special collections within the library itself. Increasingly, special collections are viewed as the high-end differentiating characteristic across research libraries. Concurrently, for users of the general collections, the differentiation lies in a flexible and customizable suite of information services, since almost every library can access the same core materials in the digital environment. Special services, moreover, are what the entire library must deliver. For the user of digital information, the ability to create custom media and personal resource management spans what used to be separate general and special collections or undergraduate and faculty support services. For physical collections, it is similarly the ability to integrate diverse resources, extract and create new materials, and develop tailored clusters for teaching. This suggests that a more holistic approach is needed to support public and technical services for special collections as well as systems for their access and discovery. It serves scholars at all levels if the focus of library departments and specialists is more on subjects than formats-that is, if librarians in a given field work across general, special, media and nonbook collections and resources that pertain to that field. Format does matter for collections security and preservation, but it shouldn't drive how we present our expertise to library users. Discoverability and usability have become so radically enhanced through a plethora of digital tools that print and digital formats can now effectively leverage and promote each other. Cataloging and acquisitions functions for "ordinary" materials are so dominated by vendor-provided services that the role of local catalogers and technical services staff is by definition to work on the out-of-the-ordinary materials, specialty languages, and rare collections. Looking at all areas of library operations in this way helps to develop an integrated model for assessing the impact of special collections.

Such functional integration within the library can lead to more effective inclusion of special collections materials and services in broad programmatic assessment initiatives. In turn, it can enable the library to better demonstrate its value to the university and all its constituencies. To assess the educational outcomes of our services and the alignment of library services with university mission will require continued creativity and research, and new metrics. The studies and essays in this volume represent important steps in that direction-important because just counting linear feet isn't useful anymore. 